\title{
DEVELOPMENT OF THE CONSTRUCTION WASTE MANAGEMENT PERFORMANCE EVALUATION TOOL (WMPET)
}

\author{
Jee-Hye Kim, Jae-Moon Kim, Hee-Sung Cha, Dong-Woo Shin \\ Dept. of Architecture \\ Ajou University \\ 5 Wonchon-Dong, Yeongtong-Gu, Suwon, Korea \\ kjh1970@empal.com
}

\begin{abstract}
Despite waste management in construction industry has a significant impact on both economical and environmental issues, the current level of waste management performance in Korean construction is reported as relatively low. To improve any type of management performance, it is necessary to diagnose the current status of the performance level. In this context, this research is aimed to identify important factors in influencing the waste management performance and to develop an evaluation tool for the purpose of assessing the level of the performance for a particular construction site. In this paper, 59 influential factors have been identified and categorized into five classes, i.e., manpower, material, method, management, and policy, in terms of the characteristics of the factors. In addition, an evaluation tool has been developed in order to effectively quantify all the 59 factors based on a thorough industry survey. The output of the Tool, which is Waste Management Index, effectively assess the level of waste management performance for a particular project and provide with the most leveraged factors in need for improvement in waste management performance.
\end{abstract}

Keywords: construction wastes, waste management performance, evaluation tool, sustainable construction environment

\section{INTRODUCTION}

\subsection{Background and Purpose}

As global climatic and ecological problems have become serious, regulations such as UNFCCC (United Nations Framework Convention on Climate Change) and laws relevant to wastes in most countries have gradually reinforced.[1] To comply with these restrictions, many construction companies are required to establish a "sustainable" construction production system. To cope with this issue, only a few large-size construction companies have established waste management guidance with instructions to reduce construction wastes and to maximize their reuse.

However, the results of the on-site case studies reveal that the present state of waste management in the construction, especially for the high-rise residential buildings, was at a low level by only providing the minimum requirement obligated by the regulations. As a result of this passive management, loss of material cost appeared to be approximately $\$ 1.0-1.2$ million per project excluding waste treatment costs and their relevant indirect costs.[13] Based on this result, it is obvious that construction wastes have a significant impact on the economical loss as well as the environmental damages. One of the reasons of this ineffectiveness is the lack of any guidance which evaluates the waste management performance and is not available on the construction site. Therefore, it is difficult to recognize how effectively a particular project is performing in terms of waste management.

In this context, this research aims to develop a tool for evaluating the effectiveness of the waste management performance in the site for the purpose of identifying the factors which influences the waste management performance. Main target of the research is focused on the wastes generated in the high-rise residential projects which occupy the most proportion in terms of Korean building industry.

\subsection{Methodology}

In order to achieve this objective, first, various waste management performance factors are identified through extensive literature reviews. Second, a questionnaire survey for construction managers who deal with wastes is conducted to analyze both weight and priority of the identified factors. Finally, an evaluation tool is developed, which is based on the factors and their weights and priorities.

As this research is still on going, the focus of this paper is on identifying waste management performance factors and establishing a conceptual model for the evaluation tool.

\section{WASTE MANAGEMENT PERFORMANCE FACTORS}

In this research, the construction management performance factors are defined as the actions which influence on decreasing wastes and increasing recycle in the construction sites. Hence, with the norm of the possibility of decreasing wastes and increasing recycle, various construction management performance factors were selected through extensive literature reviews. Literature surveys consisted of three parts: 13 papers $[4,5,6,7,8,9,10,11,12$, etc.] about construction waste published in academic journals of Korea, 7 construction waste management manuals[3, etc.] used by the sole national housing corporation and 6 major firms among the $1^{\text {st }}$ to $10^{\text {th }}$ construction firms in the rank of assessing and disclosing of construction execution capability, and 3 laws of Korea related to construction wastes. 
As the result of literature reviews referred above, it was discovered that 59 factors would have influence on decreasing wastes and increasing recycle. Authors, who have researched construction wastes for years, categorized these factors by common characteristics: manpower, material, method, management, and policy. Table 1 lists these 59 factors by category. "Manpower" category includes factors related to commitment, organization, and education for the staff of a contractor or a subcontractor who manage wastes on site. "Material" category mainly consists of the is sues related to minimizing loss of materials and use of recycled materials. The factors in "method" category include the issues on dealing with construction wastes such as carrying and storing the wastes inside of a site and taking them out of a site. The "management" category mostly represents the factors regarding contractor's waste management plan and execution, contractual conditions for waste treatment between a contractor and either a subcontractor or a waste disposal agency, and contractor's supervision on the waste personnel. Lastly, factors in "policy" category generally signify the legal issues about wastes and environmental items facilitating improved waste management.

As mentioned above, these 59 factors indicate the items which influence decreasing wastes and/or increasing recycle in the construction sites. As such, if a construction site is evaluated based on these 59 factors in terms of implementation level of the site, it is possible to assess the performance level of the project. However, since all of the factors do not have the same level of importance, it is necessary to identify the magnitude of importance of all the identified factors.

\section{RESULT OF DATA COLLECTION}

\subsection{Data Collection}

In order to investigate the magnitude of importance of for the whole 59 factors, questionnaire survey was conducted. The importance level represents both weight and priority of the factors. The organization of the questionnaire consists of suggesting 59 factors by category and requesting respondents to choose an numeric option ranged from 0 to 10 . A scale of 0 represents 'no influence on decreasing wastes and increasing recycle', while a scale of 10 represents 'the most influence on decreasing wastes and increasing recycle'.

The survey participants are in charge of managing wastes, working for general contractors in construction sites which are involved in high-rise residential projects. One hundred forty two questionnaires were distributed to construction sites located in the nearby capital area in Korea and $45(31.7 \%)$ responses were returned. Out of 45,3 were eliminated because of either missing data or improper answer. The reason for this low returning rate seems that awareness and interest in waste management of a construction site in Korea haven't been widespread yet. Only 42 questionnaires were considered to be valid for further analysis. Respondents reported had an average
Table 1 Waste Management Performance Factors

\begin{tabular}{|c|c|c|}
\hline \multicolumn{2}{|c|}{ Category } & Factor \\
\hline \multirow{7}{*}{ 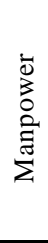 } & 1.1 & Commitment of contractor's representative of a site \\
\hline & 1.2 & Appointment of laborers only for wastes disposal \\
\hline & 1.3 & Organization breakdown structure involved in waste management \\
\hline & 1.4 & Cooperation of subcontractors \\
\hline & 1.5 & Education of the contractor's staff (engineers) \\
\hline & 1.6 & Education of the subcontractor's staff (laborers) \\
\hline & 1.7 & Preventing waste of materials by laborers \\
\hline \multirow{9}{*}{ 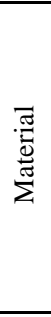 } & 2.1 & Minimizing rework on a construction phase \\
\hline & 2.2 & Design and construction using standardized materials \\
\hline & 2.3 & Collecting packed materials back by suppliers \\
\hline & 2.4 & Prefabrication of materials \\
\hline & 2.5 & Use of recycled materials \\
\hline & 2.6 & Preventing easily fragile materials from being used \\
\hline & 2.7 & Minimizing loss of materials during carrying and storing \\
\hline & 2.8 & Preventing from excess-ordered materials \\
\hline & 2.9 & Recycling of temporary materials used once in general \\
\hline \multirow{13}{*}{ 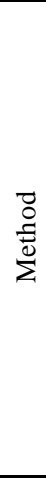 } & 3.1 & Setting up separated bins by waste type \\
\hline & 3.2 & Providing bins for collecting wastes for each subcontractor \\
\hline & 3.3 & Sorting out individual waste by type from mixed wastes \\
\hline & 3.4 & Setting up temporary bins at each building zone \\
\hline & 3.5 & Notice recyclable materials to laborers \\
\hline & 3.6 & Storing wastes at an easily accessible areas \\
\hline & 3.7 & Designate a place for storing wastes in an early stage of construction \\
\hline & 3.8 & Notice on waste tvpe, responsible staff. etc. to waste bins \\
\hline & 3.9 & Installing equipments for recycling in a site \\
\hline & 3.10 & Informing methods to deal with rest wastes after recycling \\
\hline & 3.11 & Installing an information board to notice categories for separating wastes \\
\hline & 3.12 & Preventing mixing wastes with soil \\
\hline & 3.13 & Prohibiting use of pipes for dumping down mixed wastes \\
\hline \multirow{16}{*}{ 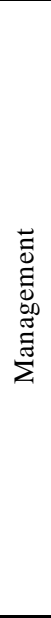 } & 4.1 & Rules on dealing with wastes by waste-generators \\
\hline & 4.2 & Contractual clauses for a subcontractor in dealing with wastes \\
\hline & 4.3 & Positive incentive for decreasing or recycling by subcontractors \\
\hline & 4.4 & Keeping a record about waste management(amounts, kinds, etc) \\
\hline & 4.5 & $\begin{array}{l}\text { Contractual clauses about the lastest method for a waste disposal agency to } \\
\text { treat wastes }\end{array}$ \\
\hline & 4.6 & Shortening a period of collecting wastes in a site \\
\hline & 4.7 & Establishing an waste management plan in an early stage of construction \\
\hline & 4.8 & Checklist on executing detailed waste management plan \\
\hline & 4.9 & Shortening a period of taking wastes out of a site \\
\hline & 4.10 & Checklist for documents to witing out and submit \\
\hline & 4.11 & Deciding an objective rate for recycling wastes \\
\hline & 4.12 & Confiming capability of a fim which treats wastes \\
\hline & 4.13 & Keeping a record about recycling wastes \\
\hline & 4.14 & Informing recycling methods and uses in a site \\
\hline & 4.15 & Checking a route periodically for a waste agency to carry wastes \\
\hline & 4.16 & Checking the last status for a waste agency to treat wastes \\
\hline \multirow{14}{*}{ 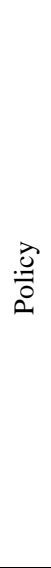 } & 5.1 & Obligatory cost estimating cost for waste treatment in a bill of quantity \\
\hline & 5.2 & $\begin{array}{l}\text { Incentive in bidding for a contractor having a plan about decreasing waste and } \\
\text { increasing recycle }\end{array}$ \\
\hline & 5.3 & Tax free for equipments treating wastes \\
\hline & 5.4 & Supervising waste management by a residential officer \\
\hline & 5.5 & Enhancing punishment for illegal treatment of wastes \\
\hline & 5.6 & Establishing criteria for quality and safety of recycled materials \\
\hline & 5.7 & Simplifying legal procedures to install equipments treating wastes \\
\hline & 5.8 & Constructing marketing structure for recycled materials \\
\hline & 5.9 & Activating development of technique to treat and recycle wastes \\
\hline & 5.10 & Raising charge for mixed wastes \\
\hline & 5.11 & $\begin{array}{l}\text { Changing the subject of a legal report from an owner to a contractor who } \\
\text { manages wastes in practice }\end{array}$ \\
\hline & 5.12 & Reducing charge for separated wastes \\
\hline & 5.13 & Database management system for construction wastes \\
\hline & 5.14 & Managing data for wastes by a head office \\
\hline
\end{tabular}


experience of 8.76 years in construction field and had an average of 2.07 years in waste management work.

\subsection{Data Analysis}

The statistical analysis of the collected data was conducted using the Statistical Package for Social Sciences. Although the authors to abstract representative factors from the 59 factors using the factor analys is as planned, it seemed meaningless in practice because the number of respondents was less than the number of variables. Due to this limitation, authors analyzed weight and priority of the factors using means of scores that respondents had provided. Analysis process includes that means of scores are calculated first, priority of the factors is arranged by the order of means, and then factors gaining means less than 6.5 are excluded from the items of the tool which evaluates the effectiveness of waste management performance, because in authors' opinion, these factors have relatively little influence on decreasing wastes and increasing recycle.

\subsection{Findings}

Based on the data analysis, it was discovered that all 7 factors in "manpower" category, 8 out of 9 factors in "material" category, 9 out of 13 factors in "method" category, 6 out of 16 factors in "management" category, and 9 out of 14 factors in "policy" category were revealed to be relatively more important in decreasing wastes and increasing recycle. Figures 1 through 5 show the factor's value and level of influence by category. (Appendix I includes mean, mode, priority of the factors.)

In the "manpower" category, 'the commitment of the leader of a site (8.07 out of 10)' and 'appointment of the laborer working only for disposal wastes (7.69 out of 10)' were identified as the more important factors than factors ( $<7.00$ out of 10) on education for a staff or organization for a waste management. (See table1 and fig.1) In addition, recognizing that all factors in this category are selected as the finalized items for the evaluation tool, it can be interpreted that human factors are most important in waste management performance.

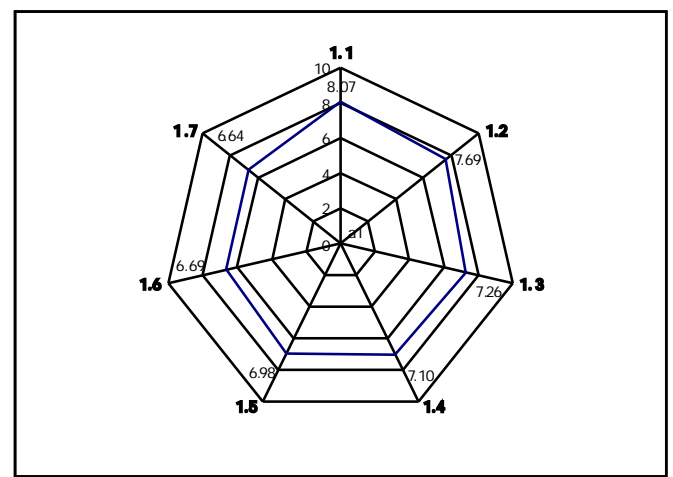

Fig. 1 Importance of the Factors in Manpower Category

In the "material" category, factors (>7.85 out of 10) such as 'minimizing rework', 'construction using standardized materials', and 'supplier's collecting packed material' were recognized to relatively have more influence in waste management performance. (See table1 and fig.2) That is, a failure or missing a material plan in the preconstruction phase or quality management in the construction phase might possibly increase more wastes in the construction phase. Therefore, this result implies that the planning of waste management in the preconstruction phase is effective for decreasing the waste and increasing the recycling as well as an effort during the construction phase.

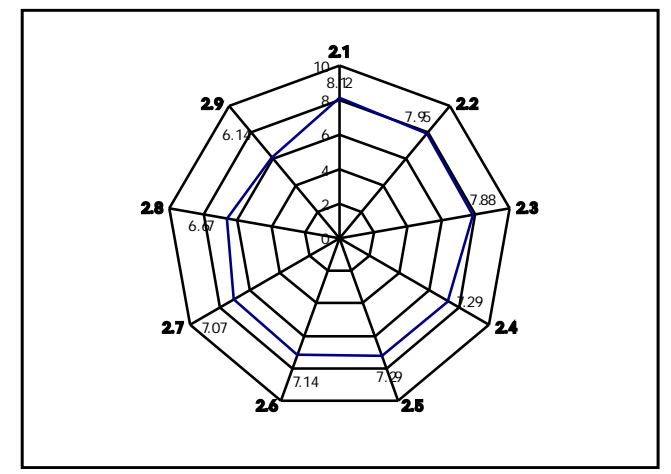

Fig. 2 Importance of the Factors in Material Category

In the "method" category, the ways to separately collect wastes by kinds, such as 'setting separated bins (7.26 out of 10)', 'providing bins for each subcontractor (7.00 out of $10)$ ', and 'sorting out mixed wastes (6.90 out of 10)', were chosen as effective factors. (See table1 and fig.3) While, factors such as 'installing equipments' or 'methods to treat wastes directly inside of the site' appeared to be less effective for waste management. This result could be caused by the environmental reasons either that existing equipments in a site do not have enough effectiveness to treat wastes or that conditions of the site does not allow wastes to be treated directly inside of the site.

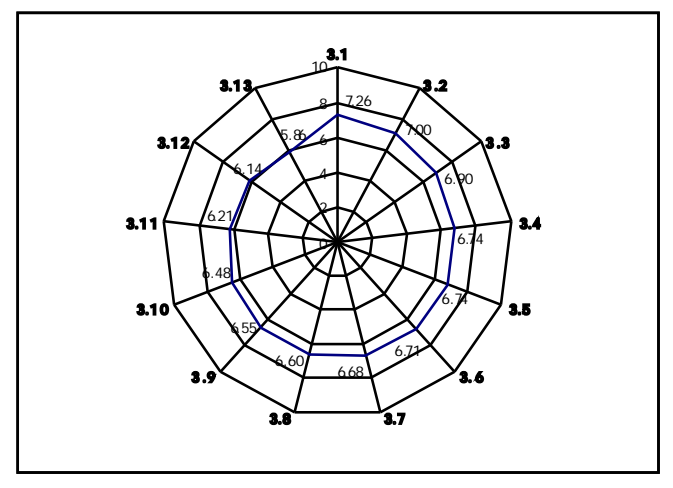

Fig. 3 Importance of the Factors in Method Category

In the "management" category, "the rule on dealing with the wastes by the waste-generators' was discovered as the most effective factor ( 7.26 out of 10 ), and 'the contractual clauses and the incentives about treating wastes' were the other effective factors (>6.60 out of 10). While the effectiveness of the factors related to 'waste management plan' and 'managing waste agencies' were found to be less effective. (See table1 and fig.4) This result can be caused by the delivery system of Korea. Legally, construction 
wastes must be managed by an owner himself or by a separated deliverer (a waste disposal agency). However, a contractor is the practical subject which manages wastes on the site. In this context, it is for granted that a contractor either wants to flow down the responsibility to subcontractor through contractual clauses or contract with a waste agency in the lump.

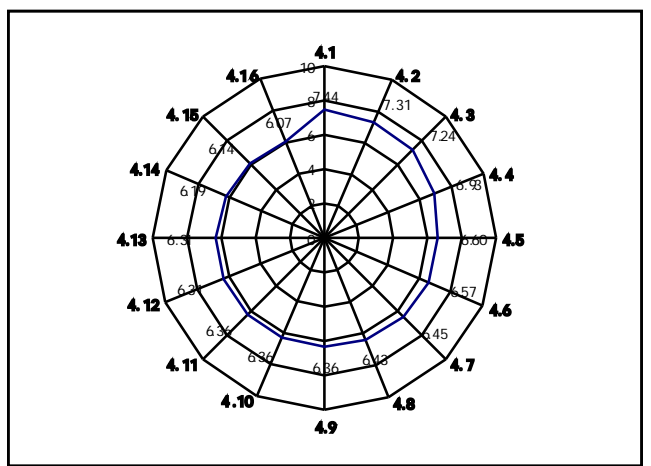

Fig. 4 Importance of the Factors in Management Category

In the "policy" category, it was found out that factors (>7.07 out of 10) related to 'obligatory cost estimating(5.1)', 'incentive and punishment for waste management' were more effective rather than factors related to 'activating development of the technique', 'changing cost of treating wastes', and 'data management for the construction wastes'. (See table1 and fig.5) Judging by this result, it is noteworthy that the effectiveness of waste management is highly dependent on the legal obligations.

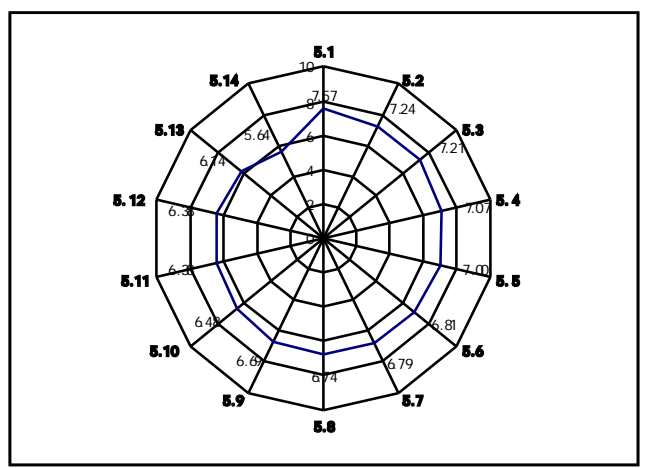

Fig. 5 Importance of the Factors in Policy Category

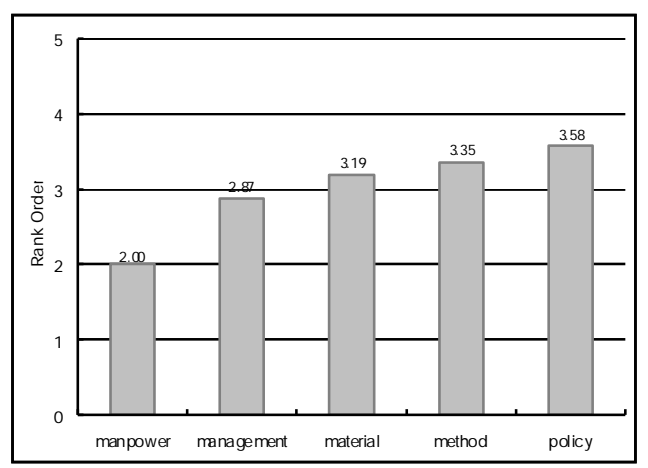

Fig. 6 Rank Order Average
Figure 6 shows the result of rank orders. This priority means the order with which those categories influence on decreasing wastes and increasing recycle. As can be seen in fig. 6, "manpower" ranks highest with a large gap from the other categories. It is noteworthy that "policy" has the least priority in influencing the waste management. It may imply that the people in charge of the waste practice must have greater commitment and interest in order to raise the effectiveness of the waste management performance.

\subsection{Bias of Findings}

As the findings shown above are the results of the questionnaire survey, of which the respondents are construction managers working for a general contractor in a construction site, this result maybe biased depending on increasing profit or convenience from the perspective of contractors. In order to overcome this bias, additional investigation needs to be conducted to gather objective opinions from the perspective of the other stakeholders such as the subcontractors and the waste disposal agencies.

\section{DEVELOPMENT OF WASTE MANAGEMENT PERFORMANCE EVALUATION TOOL (WMPET)}

\subsection{Design of the Tool}

Authors decided to use the format of the Design Effectiveness Evaluation Matrix [2], which was developed by CII design task force in 1986. This evaluation matrix was verified as an effective tool in quantitatively measuring the effectiveness of the qualitative performance by computing a score of each factor related with the design performance. Based on these advantages, it is proper to apply to the tool of evaluating the effectiveness of waste management performance in a construction site. Figure 7 shows the evaluation matrix for the performances in the manpower category. The format is similar with the CII Design Effectiveness Evaluation Matrix except the contents of performance factors and weight of each factor.

\subsection{Performance Factor and Category weights}

All 59 factors are not equally important in decreasing wastes and increasing recycle. As mentioned in section 3.2, the factors with mean value of less than 6.5 were excluded from the items included in the tool. The factors in the "policy" category were also excluded because these factors would be uncontrollable in an individual construction site. Through this process, 30 factors were finally selected in consisting of the items for the evaluation tool. In order to precisely evaluate the influence of each factor and each category on the effectiveness of the waste management performance, weights of (B) and (E) shown in table 2 were endowed based on the priority which was the result of the questionnaire survey. However, values of weights were given based on the authors' opinion. This values need to be validated for further research.

\subsection{Scoring Process}


The evaluation of the effectiveness of the waste management performance in a site is progressed in the following order. (See fig.7 and table 2)

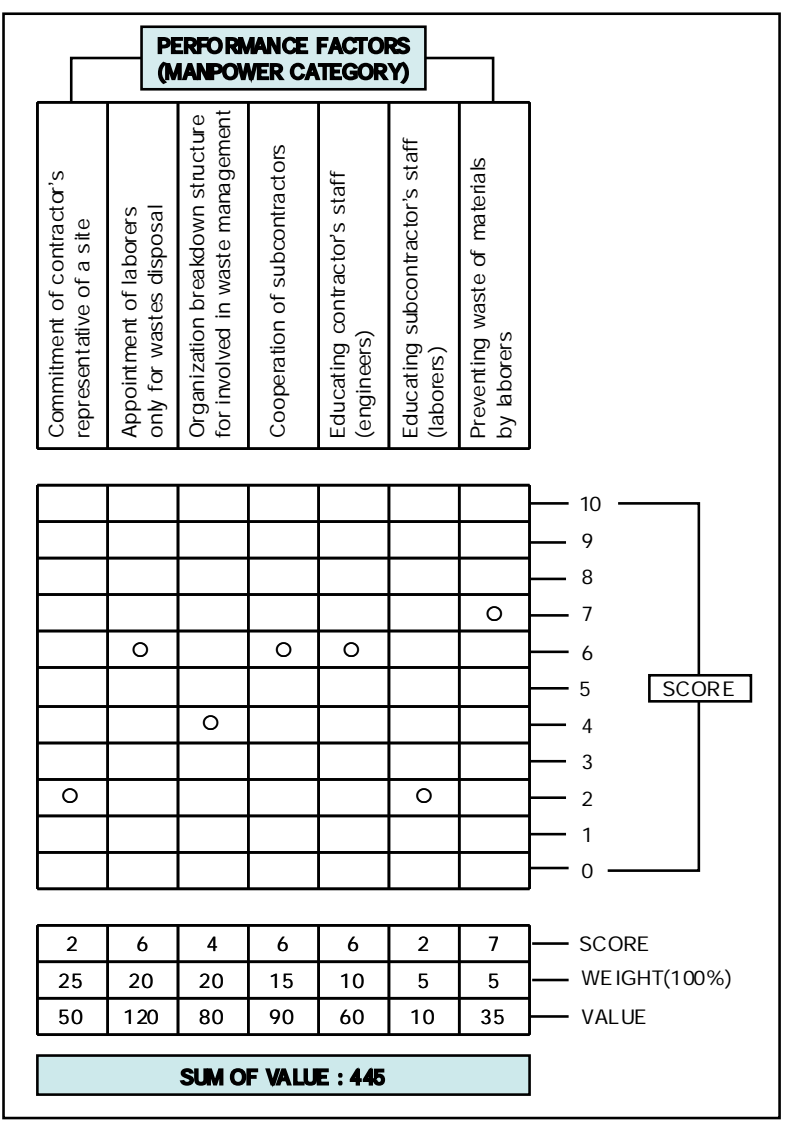

Fig. 7 Sample Matrix for Evaluating Effectiveness of Waste Management Performance

Table 2 Sample Case of Computing Waste Management Index

\begin{tabular}{|c|c|c|c|c|c|c|c|c|}
\hline category & factor & $\begin{array}{l}\text { factor score } \\
\text { (A) } \\
\text { (example) }\end{array}$ & $\begin{array}{l}\text { factor weigh } \\
\text { (B) }\end{array}$ & $\begin{array}{l}\text { value } \\
(C=A B B)\end{array}$ & $\begin{array}{l}\text { um of value } \\
\left(\mathrm{D}=\sum \mathrm{C}\right)\end{array}$ & $\begin{array}{l}\text { calevory } \\
\text { weight } \\
\text { (E) }\end{array}$ & $\begin{array}{c}\text { calespory } \\
\text { inder } \\
\text { (F=DEE) }\end{array}$ & $\begin{array}{l}\text { total } \\
\text { index } \\
\text { (G=EF) }\end{array}$ \\
\hline \multirow{7}{*}{ 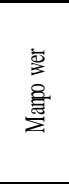 } & 1.1 & 2 & 25 & 50 & \multirow{7}{*}{445} & \multirow{7}{*}{0.35} & \multirow{7}{*}{156} & \\
\hline & 1.2 & 6 & 20 & 120 & & & & \\
\hline & 1.3 & 4 & 20 & 80 & & & & \\
\hline & 14 & 6 & 15 & 90 & & & & \\
\hline & 15 & 6 & 10 & 60 & & & & \\
\hline & 1.6 & 2 & 05 & 10 & & & & \\
\hline & 17 & 7 & 05 & 35 & & & & \\
\hline \multirow{7}{*}{ 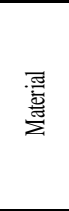 } & 2.1 & 3 & $\frac{25}{20}$ & 75 & \multirow{7}{*}{465} & \multirow{7}{*}{0.20} & \multirow{7}{*}{93} & \\
\hline & $\frac{2.2}{23}$ & $\frac{2}{5}$ & $\frac{201}{15}$ & $\frac{40}{75}$ & & & & \\
\hline & 2.4 & 6 & 10 & 60 & & & & \\
\hline & 2.5 & 7 & 10 & 70 & & & & \\
\hline & 2.6 & 9 & 10 & 90 & & & & \\
\hline & 27 & 7 & 5 & 35 & & & & \\
\hline & 2.8 & 4 & 5 & 20 & & & & 455 \\
\hline \multirow{9}{*}{$\frac{8}{2}$} & 3.1 & 7 & 25 & 175 & \multirow{9}{*}{485} & \multirow{9}{*}{0.20} & \multirow{9}{*}{97} & \\
\hline & 3.2 & 5 & 15 & 75 & & & & \\
\hline & 3.3 & 3 & 15 & 45 & & & & \\
\hline & 3.4 & 0 & 10 & 0 & & & & \\
\hline & 3.5 & 4 & 10 & 40 & & & & \\
\hline & 3.6 & 9 & 10 & 90 & & & & \\
\hline & 3.7 & 3 & 5 & 15 & & & & \\
\hline & 3.8 & 9 & 5 & 45 & & & & \\
\hline & 3.9 & 0 & 5 & 0 & & & & \\
\hline \multirow{5}{*}{ 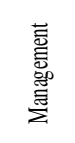 } & 4.1 & 8 & 25 & 200 & \multirow{5}{*}{435} & \multirow{5}{*}{0.25} & \multirow{5}{*}{109} & \\
\hline & 4.2 & $\frac{3}{3}$ & $\frac{25}{20}$ & 75 & & & & \\
\hline & 4.3 & 0 & 20 & 0 & & & & \\
\hline & 4.4 & 9 & 15 & 135 & & & & \\
\hline & $\frac{4.5}{16}$ & 5 & $\frac{10}{5}$ & $\frac{0}{25}$ & & & & \\
\hline
\end{tabular}

1) Choose the score of each factor in the evaluation matrix.

2) Compute the individual value of factors by multiplying the score by a weight of each factor.

3) Sum up the value by each category.

4) Compute the total index by multiplying sum of the value of each category by a weight of each category.

The total score, which is denoted to be total index, is defined as the level of the effectiveness of the waste management performance in a particular site. This index can be interpreted as one of the four ratings as described in table 3 . The index range provided in table 3 needs more indepth analysis. In this paper, the ranges are based on pilot case studies.

Table 3 Rating of Index

\begin{tabular}{|c|l|l|}
\hline Index Range & Rating & \multicolumn{1}{|c|}{ Description } \\
\hline 801-1000 & Excellent & $\begin{array}{l}\text { Waste management performance in this } \\
\text { site is very effective in decreasing wastes } \\
\text { and increasing recycling. Please keep } \\
\text { attention to waste management. }\end{array}$ \\
\hline 601-800 & Good & $\begin{array}{l}\text { Waste management performance in this } \\
\text { site is a little effective in decreasing } \\
\text { wastes and increasing recycling. If you } \\
\text { concern about weak part such as (OOO } \\
\text { weak categories and factors), the } \\
\text { effectiveness will be maximized. }\end{array}$ \\
\hline $401-600$ & Poor & $\begin{array}{l}\text { Waste management performance in this } \\
\text { site is ineffective in decreasing wastes } \\
\text { and increasing recycling. Please perform } \\
\text { factors effective such as (OOO } \\
\text { categories and factors having strong } \\
\text { influence) }\end{array}$ \\
\hline $0-400$ & Bad & $\begin{array}{l}\text { Waste management performance in this } \\
\text { site is very ineffective in decreasing } \\
\text { wastes and increasing recycling. Please } \\
\text { establish or correct waste management } \\
\text { plan of your site with referring to this } \\
\text { tool. }\end{array}$ \\
\hline
\end{tabular}

\section{DISCUSSION AND CONCLUSION}

This research is aimed at developing a tool for evaluating the effectiveness of the waste management performance in a particular site for the purpose of identifying the factors which influence on the waste management performance. Through extensive literature survey and questionnaire survey, 59 performance factors for the construction waste management were identified and significance (priority and weight) of the factors were analyzed. Furthermore, the concept of the tool to evaluate the effectiveness of the construction waste management performance was suggested.

Because this research is still on going and in the preliminary phase, there are limitations and further researches to be considered. First of all, in order to quantitatively measure the precise effectiveness of the management performance factors, sub-factors of each factor need to be identified. Value of weight for the factors and the categories also needs to be identified through additional expert interviews or works hops. Furthermore, the evaluation tool suggested in this paper should be verified by the use of the construction site. 
Although there are some limitations on this study, the proposed evaluation tool can be used as a waste management tool focusing on the scoring process, rather than just a scoring and judging mechanism. It is also important to make appropriate actions to expedite the effectiveness of waste management to better improve sustainable construction environment.

\section{APPENDIX I. Summary of Descriptive Statistical Analysis}

\begin{tabular}{|c|c|c|c|c|c|}
\hline Category & $\begin{array}{c}\text { Factor } \\
\text { Number } \\
\& \\
\text { Priority }\end{array}$ & Mean & Mode & $\begin{array}{c}\text { Std. } \\
\text { Deviation }\end{array}$ & Variance \\
\hline \multirow{7}{*}{ 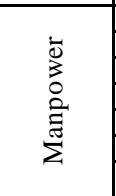 } & 11 & 8.07 & 9 & 1.79 & 3.19 \\
\hline & 12 & 7.69 & 9 & $\frac{1.17}{2.40}$ & 5.78 \\
\hline & 1.3 & 7.26 & 9 & $\frac{2.40}{2.05}$ & $\frac{0.10}{4.20}$ \\
\hline & 14 & 7.10 & 9 & 2.49 & 6.19 \\
\hline & 15 & 6.98 & 8 & 2.40 & 5.78 \\
\hline & 16 & 6.69 & 6 & 2.27 & 5.15 \\
\hline & 1.7 & 6.64 & 8 & 2.57 & 6.63 \\
\hline \multirow{9}{*}{ 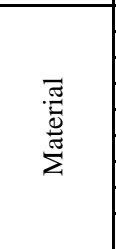 } & 21 & 8.12 & 9 & 176 & 3.08 \\
\hline & 22 & 7.95 & 9 & 192 & 3,70 \\
\hline & 23 & 7.88 & 9 & 1.80 & 3.23 \\
\hline & 24 & 7.29 & 8 & 2.18 & 4.75 \\
\hline & 25 & 729 & 8 & $\frac{2.21}{2.21}$ & 4.89 \\
\hline & 26 & 7.14 & 7 & 2.09 & 4.37 \\
\hline & 27 & 7.07 & 9 & 2.22 & 4.95 \\
\hline & 28 & 6.67 & 8 & 2.32 & 5,40 \\
\hline & 2.9 & 6.14 & 8 & 2.73 & 7.44 \\
\hline \multirow{13}{*}{ 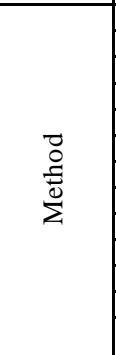 } & 31 & 726 & 8 & 159 & 254 \\
\hline & 32 & 7.00 & 9 & 2.24 & 5.02 \\
\hline & 33 & 6.90 & 7 & 1.99 & 3.94 \\
\hline & 34 & 6.74 & 6 & 1.90 & 3.61 \\
\hline & 35 & $\frac{6.14}{6.74}$ & $\frac{0}{8}$ & $\frac{1.90}{2.00}$ & $\frac{3.01}{4.00}$ \\
\hline & 36 & 6.71 & 7 & 2.03 & 4.11 \\
\hline & 37 & 6.68 & 7 & 1.94 & 3.77 \\
\hline & 38 & 6.60 & 8 & 2.10 & 4.39 \\
\hline & 39 & 6.55 & 7 & $\frac{2.10}{2.17}$ & 4.69 \\
\hline & 310 & 6.48 & 5 & 2.22 & 4.94 \\
\hline & 311 & 6.21 & 5 & 2.12 & 4.51 \\
\hline & 312 & 6.14 & 6 & 2.24 & 5.00 \\
\hline & 3.13 & 5.86 & 5 & 2.31 & 5.34 \\
\hline \multirow{16}{*}{ 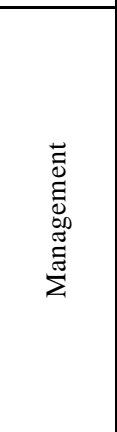 } & 41 & 7.44 & 9 & 2.44 & 595 \\
\hline & 42 & 731 & 7 & 176 & 3.10 \\
\hline & 43 & 7.24 & 8 & 2.16 & 4.67 \\
\hline & 14 & 6.93 & 7 & 2.17 & 4.70 \\
\hline & 15 & 6.60 & 7 & $\frac{2.26}{2.26}$ & $\frac{401}{512}$ \\
\hline & $\frac{16}{46}$ & $\frac{6.57}{6.57}$ & $\frac{5}{5}$ & $\frac{2.26}{2.26}$ & 5.13 \\
\hline & 47 & 6.45 & 7 & 2.07 & 4.30 \\
\hline & 48 & 6.43 & 6 & 1.84 & 3.37 \\
\hline & 19 & 6.36 & 5 & 2.63 & 6.92 \\
\hline & 410 & 6.36 & 7 & 2.10 & 4.43 \\
\hline & 411 & 6.36 & 8 & $\frac{1.37}{2.37}$ & $5 \frac{5.4}{560}$ \\
\hline & 412 & 6.31 & 7 & 2.38 & 5.68 \\
\hline & 4.13 & 6.31 & 7 & 2.16 & 4.66 \\
\hline & 4.14 & 6.19 & 8 & 2.40 & 5.77 \\
\hline & $\frac{4 \sqrt{4}}{4.15}$ & 6.14 & 7 & 2.51 & 6.32 \\
\hline & 4.16 & 6.07 & 8 & 2.68 & 7.19 \\
\hline \multirow{14}{*}{$\begin{array}{l}\stackrel{3}{0} \\
:\end{array}$} & 51 & 7.57 & 9 & 1.86 & 3.47 \\
\hline & 52 & 7.24 & 7 & 1.95 & 3.80 \\
\hline & 53 & 7.21 & 8 & 1.91 & $\begin{array}{l}3.60 \\
3.64\end{array}$ \\
\hline & 54 & 7.07 & 8 & $\frac{1.11}{2.00}$ & $\begin{array}{l}4.04 \\
4.02\end{array}$ \\
\hline & 55 & 7.00 & 9 & 2.23 & 4.98 \\
\hline & 56 & 6.81 & 9 & 2.23 & 4.99 \\
\hline & 57 & 6.79 & 8 & 2.45 & 6.03 \\
\hline & 58 & 6.74 & 6 & 2.11 & 4.44 \\
\hline & 50 & 6.69 & 6 & 2.07 & 4.27 \\
\hline & $\frac{1}{510}$ & 6.48 & 8 & 2,47 & 6.11 \\
\hline & 511 & 6.38 & 8 & 2.37 & 5.61 \\
\hline & 510 & 6.38 & 8 & 2.70 & 7.31 \\
\hline & 513 & 6.14 & 6 & 2.07 & 4.27 \\
\hline & 5.14 & 5.64 & $\frac{6}{4}$ & 2.30 & 5.31 \\
\hline
\end{tabular}

\section{ACKNOWLEDGE}

This work was supported by the ERC program of MOST. (grant R11-2005-056-03004-0)

\section{REFERENCES}

[1]Climate Change Task Force, "Second National Communication of the Republic of Korea under the UNFCCC" (Korea), 2003.

[2]CII, "Evaluation of Design Effectiveness", The Construction Industry Institute (USA), 1986.

[3]Korea National Housing Corporation, "Construction Wastes Management Manual”, KNHC (Korea), 2003.

[4]Choi, M.S., "A trial Calculation on the Disposal Cost of Construction Wastes by Using the Quantity-Per-Unit Costing Method", Journal of Architectural Institute of Korea, vol.18, n12, 2002.

[5]Hong, W.H., et al., “ The Study of Comparison and Analysis for the kinds of Construction Wastes and the Way of Disposal of these Wastes generated when Founding and Dismantling Residential Buildings", Journal of Architectural Institute of Korea, vol.20, n2, 2004.

[6]Lee, J.I., et al., "A survey on the Actual Conditions of Management and Disposal of Waste Material Produced in Construction Work", Journal of Architectural Institute of Korea, vol.14, n3, 1998.

[7]Shin, D.W., et al., "A Study on the Modeling Waste Generating Patterns Based on Construction Schedule", Journal of Architectural Institute of Korea, vol.16, n6, 2000.

[8]Yu, I.H., et al., "A Study on the Source Evaluation of Mixed Waste on Construction Sites", Journal of Architectural Institute of Korea, vol.15, n2, 1999.

[9]Koo, H.S., et al., "A Study on Plan for Reduction and Recycling Construction Waste", Conference of Architectural Institute of Korea, vol.21, n1, 2001.

[10]Lim, J.S., et al., "Disposal and Occurrence of Construction Wastes in APT's Construction", Conference of Architectural Institute of Korea, vol.18, n1, 1998.

[11]Song, T.H., et al., "Survey for Promotion of Construction Waste Recycle", Conference of Architectural Institute of Korea, vol.22, n1, 2002.

[12]Yang, K.Y., et al., "A Study on Actual Condition of Disposal of Construction Waste", Conference of Architectural Institute of Korea, vol.19, n2, 1999.

[13]Kim, J.H., et al., "Patterns and Factors Causing Construction Waste Generation in High-Rise Housing Projects in Korea : A Case Study", ERC Workshop in Korea, 2005. 